\title{
ALÉM DA CAIPIRINHA: CACHAÇA COMO SOLVENTE PARA SÍNTESE ORGÂNICA E EXTRAÇÃO DE PIGMENTO
}

\author{
Silvio Cunha ${ }^{\mathrm{a}, \mathrm{b}, *}$ e Jamille Silveira Matos ${ }^{\mathrm{a}, \mathrm{b}}$ \\ anstituto de Química, Universidade Federal da Bahia, Campus de Ondina, 40170-115, Salvador - BA, Brasil \\ 'Instituto Nacional de Ciência e Tecnologia em Energia e Ambiente, Universidade Federal da Bahia, Campus de Ondina, 40170-290 \\ Salvador - BA, Brasil
}

Recebido em 05/05/2017; aceito em 19/07/2017; publicado na web em 22/08/2017

\begin{abstract}
BEYOND CAIPIRINHA: BRAZILIAN CACHAÇA AS SOLVENT TO ORGANIC SYNTHESIS AND DYE EXTRACTION. Cachaça (brazilian sugarcane spirit) was applied for the first time as an alternative solvent in undergraduate experiments of organics synthesis, and natural dye extraction. The classical Claisen-Schmidt condensation of benzaldehyde with acetophenone and with acetone were employed to demonstrate the cachaça viability as solvent. Cachaça was also the recrystallization solvent of obtained benzalacetophenone and dibenzalacetone. The natural pigment of urucum (Bixa orellana L.) was obtained using as extractor solvent a 5\% $\mathrm{NaOH}$ solution in cachaça. Considering that in Brazil cachaça is easily available and cheaper than the $40 \%$ mixture of ethanol/ water, it can be found in every marketplace and is exported to 54 countries, the cachaça use as solvent is viable and attractive to green chemistry experiments in undergraduate courses, in Brazil and abroad.
\end{abstract}

Keywords: green chemistry; undergraduate organic chemistry experiment; Claisen-Schmidt reaction; bixin; urucum.

\section{INTRODUÇÃO}

O advento do século XXI conjurou em definitivo os químicos orgânicos e a química sustentável. Indicativo disto, uma série de artigos foi publicada por cientistas brasileiros destacando vários aspectos da sustentabilidade em química. ${ }^{1-9}$ No âmbito da educação das novas gerações de profissionais da química, é crescente o esforço de químicos brasileiros no desenvolvimento de material didático que possibilite a formação dos novos profissionais com as competências contemporâneas em química e sustentabilidade. ${ }^{8-12}$ Assim, a filosofia e a prática da química verde $(\mathrm{QV})$ é o objeto da publicação do primeiro livro em língua pátria inteiramente dedicado aos aspectos gerais da $\mathrm{QV},{ }^{13}$ e outros livros devotados aos aspectos experimentais da química orgânica verde são contribuições educacionais relevantes. ${ }^{14,15}$

Nosso envolvimento com ensino de química orgânica integrando à QV nos levou à busca de solventes alternativos para a realização de experimentos clássicos realizados nos laboratórios de ensino. ${ }^{16-19}$ Assim, o presente trabalho descreve experimentos sustentáveis de química orgânica para serem aplicadas nos cursos de graduação, tendo a cachaça como solvente de reação química e de extração e isolamento de produto natural, uma vez que o uso da cachaça como solvente atende aos princípios da QV. ${ }^{6}$

\section{Bebidas alcoólicas como solventes no ensino de química orgânica}

$\mathrm{Na}$ busca por procedimentos que utilizam metodologias mais limpas para reações químicas em experimentos para a graduação, ${ }^{1}$ a exclusão do solvente, ${ }^{16}$ quando possível, e o emprego de solventes alternativos $^{3}$ ou aparentemente pouco usuais para a realização de reações orgânicas, como o uso de vinagre por Hino e Omori, ${ }^{20}$ são temas de interesse corrente, Figura 1.

Bebidas alcoólicas como tema de ensino de química orgânica, principalmente a cerveja, foram empregadas para correlacionar o impacto da química na sociedade e como ciência mais próxima do

*e-mail: silviodc@ufba.br

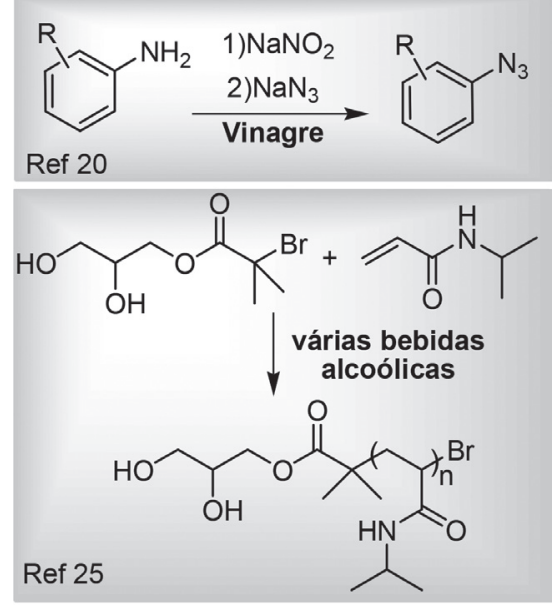

Figura 1. Exemplos de solventes não convencionais em reações orgânicas

cotidiano dos estudantes..$^{21,22}$ Misturas de flavorizantes presentes no uísque também foram empregadas em aula de destilação simples e fracionada, associada à elucidação estrutural de substâncias orgânicas. ${ }^{23}$ À parte estes aspectos, são praticamente inexistentes experimentos de ensino de química orgânica que empreguem bebidas alcoólicas como solvente de reações químicas e de extração de produto natural. Há somente alguns relatos de casos em revista de divulgação de notícias científicas de química, que informam a realização da reação de acoplamento cruzado catalisada por paládio em uísque, rum, gin, tequila e vodca, mas os procedimentos nunca foram publicados na forma de artigos. ${ }^{24}$ Mesmos que fossem, estes experimentos estariam muito distantes de serem aplicados na realidade da maioria dos laboratórios de ensino de química orgânica no Brasil.

Por outro lado, diversas bebidas alcoólicas foram empregadas como solventes alternativos em pesquisa química, como na reação de polimerização controlada da $N$-isopropil-acrilamida (Figura 1$),{ }^{25} \mathrm{e}$ como solventes em cromatografia em fase líquida de alta eficiência. ${ }^{26}$ Nesse último caso, a cachaça aparece entre as bebidas investigadas como solvente cromatográfico. 


\section{Cachaça}

A história do Brasil é profundamente marcada pela cana-de-açúcar. Primeira indústria globalizada transnacional, ${ }^{27}$ a cana-de-açúcar foi responsável por um dos mais importantes ciclos econômicos da formação da identidade brasileira, e até os dias de hoje assume relevância notável para a economia e a forma de viver de nosso povo, bastando citar os carros flex como exemplo de contribuição brasileira à questão energética. Como nos ensina Gilberto Freyre, a indústria da cana-de-açúcar ajudou a moldar a população brasileira, mas foi a responsável pela vergonhosa instalação da escravidão. ${ }^{28}$ Aqui, a população africana escravizada introduziu hábitos e costumes que, aliados a bem-aventurada nossa miscigenação, fundou a nova Roma, como preconiza Darci Ribeiro. ${ }^{29}$

Presente no folclore brasileiro, como demonstrado por José Calasans, "a cachaça, indiscutivelmente a mais conhecida e popular das nossas bebidas", ${ }^{30}$ tem a data de 13 de setembro como o dia nacional da cachaça, decisão aprovada em outubro de 2010 pela Comissão de Educação e Cultura da Câmara dos Deputados. ${ }^{31}$ Parafraseando o cancioneiro popular, "se cachaça fosse americana/cana-de-açúcar importada/bebida de bacana/era cachaçada".

A versátil química relacionada à cana-de-açúcar e seus aspectos históricos são temas que podem ser contextualizados na formação dos profissionais da química, como destacam Braibante ${ }^{32}$ e Ferreira. ${ }^{33}$ Neste sentido, o tema cachaça é estratégico, pois é bebida genuinamente brasileira. Além de ocupar posição de destaque na história do Brasil, a cachaça é motivo de pesquisa científica e inovação tecnológica, sendo relevante a contribuição do Professor Douglas W. Franco. ${ }^{34}$

O Decreto $n^{\circ}$ 6.871, de 4 de junho de 2009 estabelece que "Cachaça é a denominação típica e exclusiva da aguardente de cana produzida no Brasil, com graduação alcoólica de trinta e oito a quarenta e oito por cento em volume, a vinte graus Celsius, obtida pela destilação do mosto fermentado do caldo de cana-de-açúcar com características sensoriais peculiares, podendo ser adicionada de açúcares até seis gramas por litro". Segundo informações do Instituto Brasileiro da Cachaça - IBRAC, "no ano de 2016 a Cachaça foi exportada para mais de 54 países, com mais de 60 empresas exportadoras, gerando receita de US\$ 13,94 milhões (8,38 milhões de litros). Em 2016, os principais países de destino em valor foram Alemanha, Estados Unidos, Paraguai, Uruguai, França." 35
Tendo como referência o conhecimento popular, pesquisadores brasileiros empregaram cachaça como solvente extrator de princípios ativos de várias plantas do cerrado brasileiro ${ }^{36}$ e de capsaicinoides em pimentas. ${ }^{37}$ Todavia, não há relato de cachaça como solvente em reação química.

$\mathrm{Na}$ formação dos profissionais químicos alguns temas assumem relevância singular em função dos aspectos que encerra. A reação de Claisen-Schmidt e a extração de produto natural são dois dos temas balizares na formação experimental de cursos universitários, apresentados em vários textos didáticos de laboratórios..$^{38}$ Por estes motivos, introduzimos aqui a cachaça como solvente alternativo para experimentos envolvendo estes temas. Contudo, para que o uso de cachaça não venha a sugerir, aos estudantes em formação, apologia ao seu consumo, o instrutor deve indicar a leitura do excelente trabalho de Leal e colaboradores, sobre alcoolismo e educação química e, dos mesmos autores, sobre a origem, produção e composição química da cachaça. ${ }^{39}$

\section{Cachaça como solvente em reações de Claisen-Schmidt}

A síntese da benzalacetofenona e da dibenzalacetona são preparações clássicas executadas nos cursos experimentais para exemplificar a reação de Claisen-Schmidt, ${ }^{38}$ uma subclasse da condensação aldólica. Esta condensação foi descoberta em 1881 independentemente por Claisen ${ }^{40}$ e Schmidt, ${ }^{41}$ e tanto a síntese da benzalacetofenona quanto da dibenzalacetona constam nas publicações originais. As sínteses hoje executas nas aulas experimentais empregam praticamente os mesmos procedimentos descritos nas publicações de Claisen e Schmidt, o que torna estas preparações seculares contextualizadas historicamente. Não obstante, a síntese destas mesmas substâncias e de análogos ainda são sistematicamente investigadas e aprimoradas como experimento de ensino..$^{40,41}$

A síntese da benzalacetofenona $\mathbf{3}$ e da dibenzalacetona $\mathbf{5}$ foram aqui selecionadas para demostrar a viabilidade da cachaça como solvente alternativo em síntese orgânica, e os resultados são apresentados no Esquema 1, empregando cachaça no lugar do etanol, solvente majoritariamente utilizado nas sínteses descritas nos manuais de laboratório ${ }^{38}$ e nas publicações originais..$^{42}$

$\mathrm{Na}$ seleção de qual cachaça empregar, o critério de escolha se norteou na premissa da reprodutibilidade do experimento. Foram avaliadas as cachaças 51, Pitu e Velho Barreiro, classificadas como cachaças adoçadas (podem conter até seis gramas de açúcar por

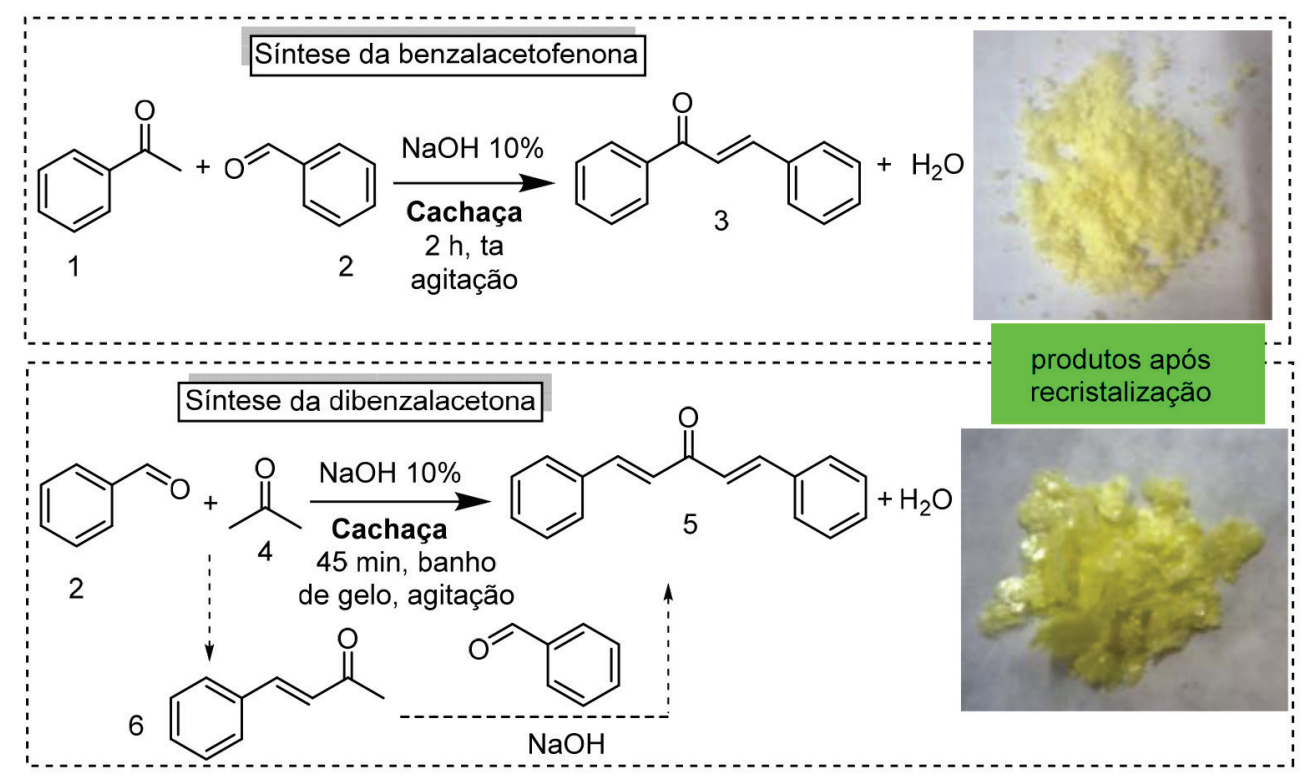

Esquema 1. Reações de Claisen-Schmidt em cachaça e fotos dos produtos sólidos $\mathbf{3}$ e 5 obtidos 
litro), de teor alcóolico similar (39\% para as duas primeiras e $40 \%$ para a última). Todas apresentaram a mesma performance durante o desenvolvimento do experimento, mas para a aplicação em aulas foi empregada a 51, pois esta tem seu processo de produção padronizado e é a mais vendida do Brasil e no mundo, sendo encontrada em mais de 50 países ${ }^{43}$ ficando assim garantido que o experimento pode ser reproduzido em qualquer parte do Brasil e nos países onde ela é comercializada. Todavia, o professor da disciplina que adotar a estratégia de aula aqui apresentada pode estimular os estudantes a investigarem a eficácia de cachaças de qualquer produtor, inclusive locais, desde que economicamente viável. Contudo, pode ocorrer variação nos rendimentos aqui descritos se cachaças com diferentes teores alcoólicos forem utilizadas.

Para efeito de comparação, foi adaptado o procedimento de síntese da benzalacetofenona descrito no livro de Soares e colaboradores, ${ }^{38}$ porém usando cachaça como solvente, como mostrado no Esquema 1.

Diferentemente do que ocorre com os solventes clássicos para esta síntese, não houve a precipitação do sólido no término da reação ( $2 \mathrm{~h}$ ), mesmo deixando o frasco reacional em banho de gelo por $1 \mathrm{~h}$. Para contornar esta situação, foi possível padronizar o procedimento de formação do sólido aquecendo a mistura reacional até a ebulição, após o término da reação, seguido da adição de mais cachaça previamente aquecida (detalhes no experimental). Nesse momento a mistura apresenta duas fases, um óleo de coloração castanha escura e uma solução amarelada e opaca que, ao retirar do aquecimento e resfriar em banho de gelo concomitante à adição de gelo triturado, em repouso forma o precipitado esperado.

Na purificação tradicionalmente se emprega recristalização em etanol. ${ }^{38,42}$ Aqui resolvemos manter a cachaça também na etapa de recristalização, o que demandou o desenvolvimento de procedimento robusto para ser reproduzido pelos estudantes. Assim, ao sólido formado foi adicionado cachaça até seu recobrimento, e só então a mistura deve ser aquecida. A adição lenta de cachaça quente proporciona a completa solubilização do sólido, e então a solução deve ser imediatamente removida do aquecimento pois, se for aquecida por muito tempo, há perda do etanol da cachaça e a solução se torna turva, provocando precipitação rápida de um óleo e não do sólido cristalino. É possível sempre contornar este fato, caso ocorra, aquecendo novamente a mistura e adicionando mais cachaça quente, pois a solução volta a ficar límpida e os cristais do sólido são formados lentamente. Seguindo estes cuidados, cessando o aquecimento assim que se observa a solubilização, a mistura deve ser resfriada inicialmente ao ar para que a precipitação ocorra lentamente, seguida de resfriamento em banho de gelo com a adição de gelo triturado ao frasco. Quando fria, a solução é turva de coloração esbranquiçada e os cristais amarelo pálidos (Figuras 3S). O sólido assim obtido, cuja foto se encontra no Esquema 1, tem aspecto idêntico ao preparado com solventes tradicionais.

Para obter uma massa maior do sólido e aumentar o rendimento da reação pode-se ainda deixar o filtrado na geladeira por no mínimo 24 h. Para fins didáticos preferiu-se descartar o filtrado, calculando o rendimento apenas com o precipitado obtido imediatamente após a recristalização.

Os reagentes benzaldeído e acetofonenona foram empregados tanto como fornecidos pelas empresas quanto recém destilados. Nestas duas situações a benzalacetofenona 3 foi obtida e os rendimentos foram $50 \%$ e $54 \%$, respectivamente. Portanto, se os reagentes usados forem não envelhecidos isto não afeta significativamente o rendimento obtido.

A benzalacetofenona 3 foi caracterizada através da determinação do ponto de fusão e da obtenção do espectro na região do infravermelho, e comparada com amostra autêntica, obtida pela rota tradicional. Na literatura para ensino de química orgânica experimental, o rendimento típico indicado para a benzalacetofenona é $65-75 \% .^{38,42}$
Com os cuidados apontados para o emprego de cachaça como solvente da reação e de recristalização, a síntese foi empregada em turma de 12 estudantes atendidas por um instrutor, sendo possível realizar o experimento em uma aula prática na graduação de 3-4 horas de duração.

O sucesso da reação de Claisen-Schimdt empregando cachaça como solvente alternativo nos levou a aplicar esta abordagem também na síntese da dibenzalacetona $\mathbf{5}$, pois assim o professor pode lançar mão de mais esta possibilidade, levando em conta a disponibilidade dos reagentes e a dimensão da turma de estudantes, o que pode implicar no consumo considerável da acetofenona do primeiro exemplo. Como a acetona é muito frequente nos laboratórios de ensino, passa a ser uma opção para aqueles que desejarem implementar os experimentos aqui descritos. Entretanto, foi necessário adaptar o procedimento descrito na literatura ${ }^{38,42}$ para que fosse obtido êxito na síntese de $\mathbf{5}$ em cachaça, Esquema 1. O experimento demanda duas sessões de aulas experimentais, sendo a reação executada na primeira etapa, e na segunda ocorre o isolamento e a purificação. A reação é executada em no máximo uma hora, sendo recomendado associar esta primeira aula a outro experimento (que pode ser a extração do pigmento natural do urucum abaixo descrito), considerando uma aula de 3-4 h de duração.

Novamente aqui, diferentemente do que ocorre quando são empregados os solventes tradicionais para a síntese da dibenzalacetona, ${ }^{38,42}$ ao término da reação não se observa o sólido, mas sim duas fases, um óleo de coloração castanha e uma solução amarelada. Esta mistura foi deixada resfriando na geladeira por uma semana, sendo trabalhada na aula consecutiva (após 24 h já se observa formação do sólido). De forma análoga ao procedimento de recristalizado acima descrito, o solvente foi a cachaça, empregando procedimento desenvolvido para este fim (detalhes no experimental e Figura 4S). A dibenzalacetona 5 foi obtida em $47 \%$ de rendimento, comparável aos rendimentos de 40-60\% mencionados na literatura específica para o ensino de química orgânica experimental, ${ }^{38,42}$ e foi caracterizada através da determinação do ponto de fusão e da obtenção do espectro na região do infravermelho, e comparados com amostra autêntica.

$\mathrm{Na}$ formação da dibenzalacetona duas reações consecutivas ocorrem, sendo que na primeira se forma in situ o intermediário benzalacetona 6, que em seguida reage com o benzaldeído produzindo a dibenzalacetona 5. Esta transformação é uma boa oportunidade para o instrutor apresentar e explicar o emprego de vários termos inerentes à síntese orgânica. Assim, podem ser adequadamente trabalhadas na aula experimental os conceitos de reações multicomponentes, pseudo multicomponentes, reações bidirecionais e o significado da formação de uma substância in situ, Esquema 1.

\section{Cachaça como solvente de extração do pigmento do urucum}

Se cachaça é a bebida mais genuinamente brasileira, o urucum (Bixa orellana $L$.) está na formação ancestral da nossa identidade pois há registro que, no primeiro encontro com os moradores originais do Brasil, os portugueses foram presenteados com urucum como boas-vindas da população indígena, como nos conta Pinto. ${ }^{44}$ Os índios brasileiros já usavam os pigmentos da semente de urucum na pintura corporal e de artefatos.

A extração do pigmento do urucum já foi tema de aula experimental, onde foram avaliados os solventes hexano e acetona, e soluções de $\mathrm{NaHCO}_{3} 15 \%$ e $\mathrm{NaOH} 5 \%$, sendo este último o mais eficaz para a extração seletiva das biximas, como descrito na aula desenvolvida. ${ }^{45}$ Para ampliar a aplicação da cachaça como solvente em aulas experimentais de química orgânica, revisitamos a proposta da aula original, agora investigando o emprego da cachaça na extração deste pigmento natural, Figura 2. 


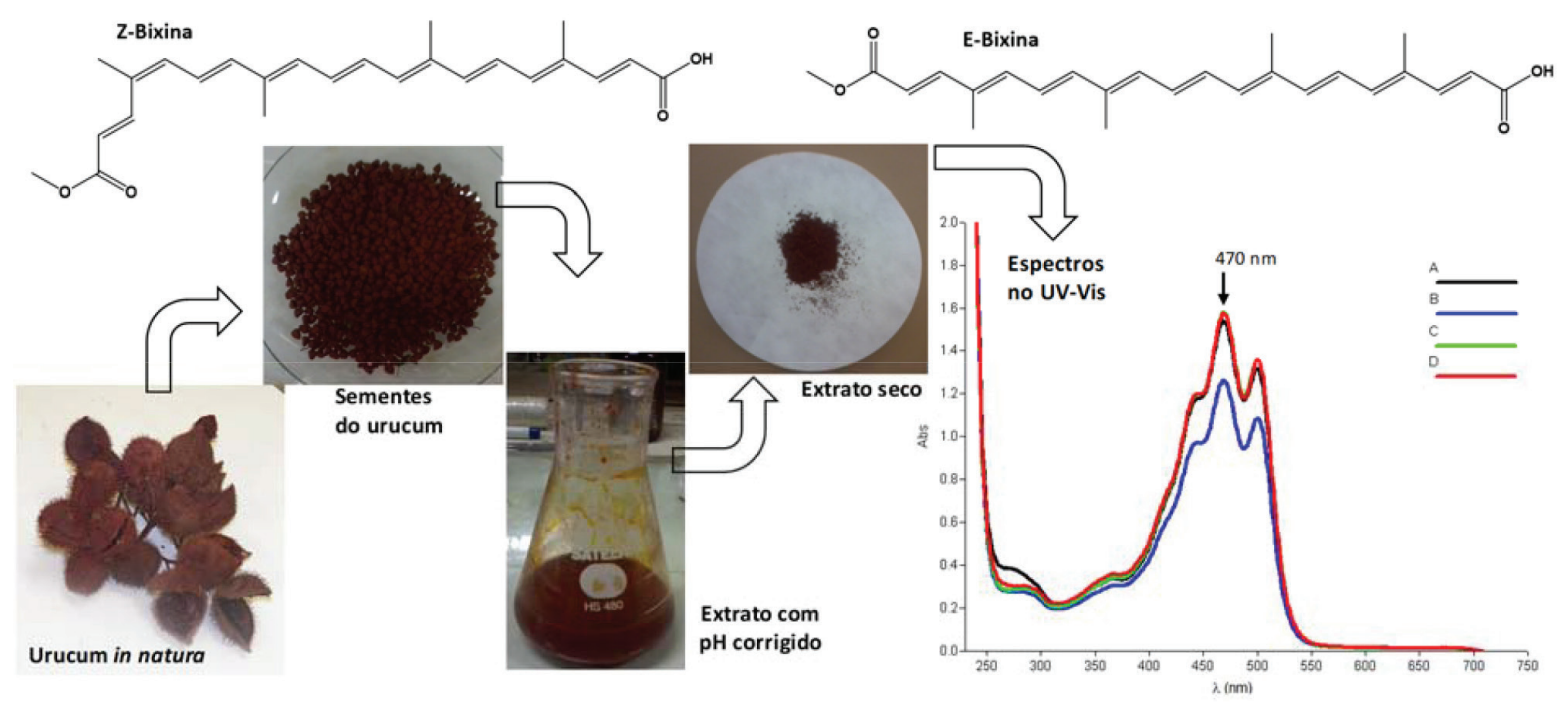

Figura 2. Estruturas das bixinas e representação das etapas da extração do pigmento do urucum (da esquerda para direita): urucum in natura, sementes, extrato, sólido obtido e espectros de absorção na região do $\mathrm{UV}$-Vis em $\mathrm{CHCl}_{3}\left(20 \mathrm{mg} \mathrm{L}^{-1}\right.$ ) nas diferentes condições de extração com $\mathrm{NaOH} 5 \%$ (A-linha preta: cachaça; B-linha azul: água; C-linha verde: cachaça/sonicação; D-linha vermelha: água/sonicação)

Para que a extração do pigmento da semente do urucum possa ser executada na mesma aula da síntese da dibenzalacetona, o tempo originalmente descrito ${ }^{45}$ de contato das sementes com a solução extratora foi reduzido de 30 para 5 minutos, o que pode levar a variação nos rendimentos. Como pode haver também variações em função de questões geográficas e/ou de sazonalidade, a mesma amostra de sementes foi extraída com solução $\mathrm{NaOH} 5 \%$, tanto aquosa quanto em cachaça, com 5 minutos de contato das sementes com as soluções extratoras.

Adicionalmente, foi investigado o efeito de sonicação empregando os dois tipos de solventes, realizando extrações em triplicata para as condições avaliadas, Tabela 1. Os sólidos obtidos de cada extrato foram caracterizados pela comparação dos espectros na região do infravermelho, e todos foram idênticos para as quatro condições de extração (para o extraído com cachaça ver Figuras 5S), e através da comparação dos espectros na região do UV-Vis com os descritos na literatura. A quantificação da bixina nos extratos seguiu o mesmo procedimento já descrito, que emprega uma simples medida da absorção por espectrofotometria UV-Vis no comprimento de onda já conhecido para esta quantificação (470 nm para solução do extrato em $\mathrm{CHCl}_{3}$, Figura 2). ${ }^{45}$

Tabela 1. Rendimentos do extrato e da bixina em função da condição de extração das sementes de urucum

\begin{tabular}{lcc}
\hline Método de extração & $\begin{array}{c}\text { Rendimento da } \\
\text { extração }^{\mathrm{b}}(\%)\end{array}$ & $\begin{array}{c}\text { Rendimento de } \\
\text { bixina }(\%)\end{array}$ \\
\hline A: cachaça $^{\mathrm{a}}$ : água & $2,99 \pm 0,82$ & $2,39 \pm 1,77$ \\
C: cachaça/ultrassom & $3,80 \pm 0,35$ & $2,15 \pm 0,96$ \\
D: água/ultrassom & $2,48 \pm 0,66$ & $3,07 \pm 0,60$ \\
\hline
\end{tabular}

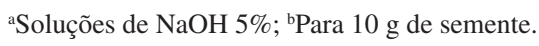

A análise da Tabela 1 revela que a redução do tempo de extração não compromete a eficácia do experimento no contexto de aula de graduação. A extração com solução aquosa de $\mathrm{NaOH}$ $5 \%$, bem como em solução de $\mathrm{NaOH} 5 \%$ em cachaça, com e sem sonicação, não apresentaram diferenças significativas, Tabela 1 (Figura 6S). Há apenas uma leve tendência de melhor eficácia no emprego de ultrassom pois, apesar dos rendimentos médios do extrato serem menores, os teores de bixina são maiores, indicando maior seletividade na extração. Dessa forma, é viável o emprego de cachaça como solvente alternativo para a extração do pigmento da semente de urucum no contexto de aula experimental, com ou sem o emprego da sonicação.

Duas estratégias de aulas podem ser adotadas. Numa, o extrato é obtido é deixado secar ao ar por uma semana, de tal forma que na aula consecutiva dá-se a caracterização e as quantificações do extrato e do teor de bixina. Nesta estratégia, a extração é associada à síntese da dibenzalacetona 5 como mencionado acima. Numa segunda, quando a reação de Claisen-Schmidt não é objeto do curso experimental em questão, ou quando a benzalacetofenona 3 é sintetizada preferencialmente à dibenzalacetona $\mathbf{5}$, é possível seguir o procedimento já conhecido de secar o extrato em estufa na mesma aula da sua obtenção e seguir à identificação e quantificação. ${ }^{45}$ Cabe ao professor decidir qual estratégia adotar em função da natureza do curso e da infraestrutura disponível.

\section{CONCLUSÃO}

O uso da cachaça como solvente alternativo em experimentos de química orgânica usados em aulas práticas na graduação se mostrou uma alternativa viável, tanto na reação de Claisen-Schmidt quanto na extração de produto natural. As sínteses da dibenzalacetona e benzalacetofenona empregando cachaça como solvente de reação e de recristalização, bem como a extração da bixina das sementes de urucum com a solução de $\mathrm{NaOH}$ em cachaça, apresentaram resultados satisfatórios e comparáveis aos métodos tradicionais da literatura de ensino experimental de química orgânica.

Primeiro relato de cachaça como solvente de reação química, o uso da cachaça como solvente atende aos princípios da Química Verde e torna as aulas práticas mais lúdicas e atraentes aos estudantes. O aroma adocicado que invade o laboratório é um agradável diferencial que a todos satisfaz e demostra que a cachaça poder ser valorizada para além da caipirinha. ${ }^{46}$

\section{PARTE EXPERIMENTAL}

Os pontos de fusão foram determinados em um aparelho de placa aquecida Microquímica MQAPF 301 e não foram corrigidos. Os espectros na região do infravermelho foram de obtidos em disco de $\mathrm{KBr}$ ou filme, em um aparelho SHIMADZU IR Affinity-1. Os 
espectros de absorção molecular na região do visível-ultravioleta foram obtidos em solução de clorofórmio, em um espectrofotômetro UV-VIS Cary 50Conc. O banho de ultrassom empregado foi da marca UNIQUE UltraSonic Cleaner USC-3300, $40 \mathrm{kHZ}, 8,5 \mathrm{~L}$ (cesto: 47 x 11,5 x $10 \mathrm{~cm}$; cuba/tanque: 50 x $13 \times 15 \mathrm{~cm}$ ). A acetona foi empregada nas reações sem tratamento prévio; o benzaldeído e a acetofenona foram destilados antes do uso. A cachaça utilizada foi da marca 51. As sementes de urucum foram adquiridas na região do baixo sul da Bahia, em Serra Grande, distrito de Valença, em novembro de 2012.

\section{Reações de Claisen-Schmidt}

\section{Síntese da benzalacetofenona 3 em caçhaça}

Em um Erlenmeyer de $125 \mathrm{~mL}$ preparar uma mistura de $25 \mathrm{~mL}$ de solução aquosa de hidróxido de sódio $10 \%, 15 \mathrm{~mL}$ de cachaça e $6 \mathrm{~mL}(50 \mathrm{mmol})$ de acetofenona. Em seguida resfriar a mistura em banho de gelo e sob agitação constante adicionar $5 \mathrm{~mL}(50 \mathrm{mmol})$ de benzaldeído. Após a adição do benzaldeído, manter a mistura sob agitação magnética a temperatura ambiente por $2 \mathrm{~h}$. Ao término deste tempo, aquecer a mistura até a ebulição e adicionar porções de cachaça previamente aquecida até completa solubilização (são necessários cerca de $40 \mathrm{~mL}$ ). Em seguida, retirar o aquecimento, esperar o Erlemneyer atingir a temperatura ambiente e então resfriar em banho de gelo e adicionar gelo triturado à mistura. Filtrar a vácuo o sólido que se forma, lavar com água destilada gelada e transferir o sólido impuro para um Erlenmeyer de $125 \mathrm{~mL}$ e adicionar aproximadamente $5 \mathrm{~mL}$ de cachaça ao sólido e aquecer a mistura até a ebulição. Adicionar gradativamente cachaça previamente aquecida, até a solubilização do mesmo. Retirar do aquecimento assim que se observar a solubilização. Esperar o Erlenmeyer atingir a temperatura ambiente, resfriar em banho de gelo e adicionar gelo triturado à mistura. Em seguida filtrar a vácuo o sólido amarelo-pálido que se forma, lavar com água destilada gelada e secar ao ar por uma semana. Determinar a massa e determinar o ponto de fusão e obter o espectro na região do infravermelho.

A massa de 3 após a recristalização foi de $2,8254 \mathrm{~g}$ com rendimento de $54 \%$, pf $53,9-54,3{ }^{\circ} \mathrm{C}$ (Lit. ${ }^{38} 56-57{ }^{\circ} \mathrm{C}$ ).

Opcionalmente, as quantidades podem ser reduzidas à metade sem redução significativa do rendimento. Também é possível, após a recristalização, secar o sólido em estufa por $1 \mathrm{~h}$ e proceder à caracterização, ${ }^{38}$ dependendo da duração da aula.

\section{Síntese da dibenzalacetona 5 em caçhaça}

Em um Erlenmeyer de $125 \mathrm{~mL}$ pesar $4 \mathrm{~g}$ de $\mathrm{NaOH}$ e logo em seguida adicionar $40 \mathrm{~mL}$ de água e $35 \mathrm{~mL}$ de cachaça. Homogeneizar até completa dissolução e resfriar a solução em banho de gelo e adicionar, aos poucos e sob agitação magnética, metade da solução previamente preparada de 4,2 $\mathrm{mL}$ (40 $\mathrm{mmol})$ de benzaldeído e 1,6 $\mathrm{mL}$ (20 mmol) de acetona. Deixar a mistura em banho de gelo e sob agitação por 15 min. Após esse tempo adicionar lentamente a outra metade da solução de benzaldeído e acetona. Deixar reagindo por mais 30 min. Após este tempo formam duas fases, um óleo de coloração castanha e uma solução amarelada. Tampar o Erlenmeyer com rolha e colocar na geladeira por uma semana. Após esse tempo, filtrar a vácuo, lavar com água destilada gelada e recristalizar o sólido obtido em cachaça. Adicionar aproximadamente $5 \mathrm{~mL}$ de cachaça ao sólido obtido e aquecer a mistura até a ebulição. Adicionar gradativamente cachaça quente, porém não ocorrerá a completa solubilização do sólido. Separar por decantação o óleo da solução. Colocar a solução em banho de gelo e adicionar gelo triturado; forma-se um precipitado amarelo. Adicionar ao óleo cachaça quente para a solubilização. O óleo não irá solubilizar completamente, a solução ficará amarela e o óleo em uma coloração mais clara. Colocar essa mistura em banho de gelo e também adicionar gelo triturado; forma-se um precipitado amarelo similar ao anterior. Filtrar as duas misturas a vácuo, em um papel previamente pesado, lavar com água destilada gelada e secar ao ar por uma semana. Determinar a massa e determinar o ponto de fusão e obter o espectro na região do infravermelho.

A massa total de 5, após a recristalização, foi de 2,4212 g com $47 \%$ de rendimento, pf $100,7-101,4{ }^{\circ} \mathrm{C}\left(\right.$ Lit. $\left.^{42} 110-112{ }^{\circ} \mathrm{C}\right)$.

\section{Extração da bixina das sementes de urucum}

\section{Método 1: cachaça como solvente}

Em um erlenmeyer de $125 \mathrm{~mL}$ pesar $2 \mathrm{~g}$ de $\mathrm{NaOH}$ e logo em seguida adicionar $40 \mathrm{~mL}$ de cachaça. Homogeneizar até completa dissolução e adicionar $10 \mathrm{~g}$ de sementes de urucum. Agitar manualmente por $5 \mathrm{~min}$. Ao término deste tempo, separar as sementes por filtração simples e ao filtrado adicionar, com homogeneização, $\mathrm{HCl}$ concentrado até $\mathrm{pH} 4$. Filtrar a vácuo usando papel de filtro previamente pesado, lavar o sólido com água destilada e secar ao ar por uma semana. Após este tempo, pesar a amostra e obter o espectro na região do infravermelho. Numa triplicata de experimentos, as massas dos sólidos obtidos foram 262,6, 315,5 e 323,9 mg.

\section{Método 2: cachaça como solvente com irradiação de ultrassom}

Em um balão de fundo redondo de $125 \mathrm{~mL}$ pesar $2 \mathrm{~g}$ de $\mathrm{NaOH}$ e logo em seguida adicionar $40 \mathrm{~mL}$ de cachaça. Homogeneizar até completa dissolução e adicionar $10 \mathrm{~g}$ de sementes de urucum. Levar o balão ao banho de ultrassom com água a temperatura ambiente e irradiar na potência máxima por $5 \mathrm{~min}$. Ao término deste tempo, separar as sementes por filtração simples e ao filtrado adicionar, com homogeneização, $\mathrm{HCl}$ concentrado até $\mathrm{pH} 4$. Filtrar a vácuo usando papel de filtro previamente pesado, lavar o sólido com água destilada e secar ao ar por uma semana. Após este tempo, pesar a amostra e obter o espectro na região do infravermelho. Numa triplicata de experimentos, as massas dos sólidos obtidos foram 217,6, 263,3 e 264,3 mg.

\section{Caracterização por espectroscopia na região de UV-Vis}

Preparar solução de concentração $20 \mathrm{mg} \mathrm{L}^{-1}$ : em um balão volumétrico de $50 \mathrm{~mL}$ adicionar $5 \mathrm{mg}$ do sólido obtido de cada extração da semente de urucum e avolumar com clorofórmio. Transferir 5 $\mathrm{mL}$ dessa solução para balão volumétrico de $25 \mathrm{~mL}$ e avolumar com clorofórmio. Empregando esta última solução obter o espectro na região do UV-Vis, anotar o valor da absorção em $470 \mathrm{~nm}$ e calcular a concentração de bixina. ${ }^{45}$

\section{MATERIAL SUPLEMENTAR}

Espectros na região do infravermelho, fotos da sequência da purificação em cachaça da benzalacetofenona, da benzalacetofenona, e da sequência da obtenção do pigmento sólido do urucum estão disponíveis em http://quimicanova.sbq.org.br, na forma de arquivo PDF, com acesso livre.

\section{AGRADECIMENTOS}

Os autores agradecem o suporte financeiro do Conselho Nacional de Desenvolvimento Científico e Tecnológico - CNPq, Coordenação de Aperfeiçoamento de Pessoal de Nível Superior - CAPES, e Fundação de Amparo à Pesquisa do Estado da Bahia - FAPESB. Também agradecemos a concessão a bolsa de produtividade em pesquisa do CNPq a S. Cunha, e à Professora A. M. Aleixo da UNIMEP, cujo convite permitiu aplicar o experimento aqui proposto em minicurso. Também agradecemos a ajuda do Professor W. A. Lopes com o Graphica Abstract. 


\section{REFERÊNCIAS}

1. Sanseverino, A. M.; Quim. Nova 2000, 23, 102.

2. Dupont, J.; Quim. Nova 2000, 23, 825.

3. da Silva, F. M.; Jones Jr, J.; Quim. Nova 2001, 24, 646.

4. Sanseverino, A. M.; Quim. Nova 2002, 25, 660.

5. Sanseverino, A. M.; Ciência Hoje 2002, 31, 20.

6. Lenardão, E. J.; Freitag, R. A.; Dabdoub. M. J.; Batista, A. C. F.; Silveira, C. C.; Quim. Nova 2003, 26, 123.

7. Farias, L. A., Fávaro, D. I. T.; Quim. Nova 2011, 34, 1089.

8. Zandonai, D. P.; Saqueto, K. C.; Abreu, S. C. S. R.; Lopes, A. P.; Zuin, V. G.; Rev. Virtual Quim. 2014, 6, 73.

9. Corrêa, A. G.; Zuin, V. G.; Ferreira, V. F.; Vazquez, P. G.; Pure Appl. Chem. 2013, 85, 1643.

10. Marques, M. V.; Bisol, T. B.; Sá, M. M.; Quim. Nova 2012, 35, 1696; Bisol, T. B.; Marques, M. V.; Rossa, T. A.; Nascimento, M. G.; Sá, M. M.; Quim. Nova 2012, 35, 1260.

11. Konrath, E. L.; Piedade, M.; Eifler-Lima, V. L.; Quim. Nova 2012, 35, 1887.

12. Regueira, J. L. L. F.; de Freitas, J. J. R.; de Freitas Filho, J. R; Quim. Nova 2016, 39, 1019.

13. Corrêa, A. G.; Zuin, V. G.; Química Verde: Fundamentos e Aplicações, EdUFSCar: São Carlos, 2009.

14. Pinto, C. P.; Silva, B. V.; A Química Perto de Você: Experimentos de Química Orgânica, Sociedade Brasileira de Química: São Paulo, 2012.

15. Corrêa, A. G., de Oliveira, K. T., Paixão, M. W., Brocksom, T. J.; Química Orgânica Experimental: Uma Abordagem de Química Verde, Editora Campus-Elsevier: São Paulo, 2016.

16. Cunha, S.; Costa, O. B. S.; Santana, L. L. B.; Lopes, W. A.; Quim. Nova 2015, 38, 874; para um contexto mais amplo ver: Cunha, S.; Santana, L. L. B.; J. Braz. Chem. Soc. 2017, 28, 1137.

17. Cunha, S.; Santos Filho, R. F.; Riatto, V. B.; Dourado, G. A. A.; Quim. Nova 2013, 36, 190.

18. Cunha, S.; de Santana, L. L. B.; Quim. Nova 2012, 35, 642; Cunha, S.; Iunes, C. E. M.; Oliveira, C. C.; de Santana, L. L. B.; Quim. Nova 2015, 38,1125 .

19. Cunha, S.; Lustosa, D. M.; Conceição, N. D.; Fascio, M.; Magalhães, V.; Quim. Nova 2012, 35, 638.

20. Hino, K. N.; Omori, A. T.; Quim. Nova 2015, 38,156.

21. Rosa, N. A.; Afonso, J. C.; Quim. Nova Esc. 2015, 37, 98.

22. Korolija, J. N.; Plavsic, J. V.; Marinkovic, D.; Mandic, L. M.; J. Chem. Educ. 2012, 89, 605.

23. Wan, H.; Djokic, N.; Brown, B. A.; Kwon, Y.; J. Chem. Educ. 2014, 91, 123.

24. Ritter, S. K.; Chem. Eng. News 2011, Sept. 12, 24.

25. Waldron, C.; Zhang, Q.; Li, Z.; Nikolaou, V.; Nurumbetov, G.; Godfrey, J.; McHale, R.; Yilmaz, G.; Randev, R. K.; Girault, M.; McEwan, K.; Haddleton, D. M.; Droesbeke, M.; Haddleton, A. J.; Wilson, P.; Simula, A.; Collins, J.; Lloyd, D. J.; Burns, J. A.; Summers, C.; Houben, C.; Anastasaki, A.; Li, M.; Becer, C. R.; Kiviaho, J. K.; Risangud, N.; Polym. Chem. 2014, 5, 57.

26. Welch, C. J.; Nowak, T.; Joyce, L. A.; Regalado, E. L. Cocktail; ACS Sustainable Chem. Eng. 2015, 3, 1000.

27. Furtado, C.; Formação Econômica do Brasil, Publifolha: São Paulo, 2000.

28. Freyre, G.; Casa-Grande e Senzala, 25ª ed., José Olympio Editora SA: Rio de Janeiro, 1987.

29. Ribeiro, D.; O Povo Brasileiro - A Formação e o Sentido do Brasil, Círculo do Livro LTDA: São Paulo, 1995.

30. Calasans, J.; Caçhaça, Moça Branca: um Estudo do Folclore, EDUFBA: Salvador, 2014.

31. http://www2.camara.leg.br/atividade-legislativa/comissoes/comissoespermanentes/ccult/documentos/relatorios-de-atividades/2016-balanco- das-atividades-do-ano/relatorio-de-atividades-de-2016, acessada em agosto de 2017.

32. Braibante, M. E. F.; Pazinato, M. S.; da Rocha, T. R.; Friedrich, L. S.; Nardy, F. C.; Quim. Nova Esc. 2013, 35, 3.

33. Ferreira, V. F.; Rocha, D. R.; Silva, F. C.; Quim. Nova 2009, 32, 623.

34. Para publicações representativas ver: Garcia, A. C.; Serafim, F. A. T.; De Keukeleire, D.; Franco, D. W.; J. Braz. Chem. Soc. 2015, 26, 57; Serafim, F. A. T.; Seixas, F. R. F.; Da Silva, A. A.; Galinaro, C. A.; Nascimento, E. S. P.; Buchviser, S. F.; Odello, L.; Franco, D. W.; J. Braz. Chem. Soc. 2013, 24, 973; Serafim, F. A. T.; Galinaro, C. A.; Da Silva, A. A.; Buchviser, S. F.; Nascimento, E. S. P.; Novaes, F. V.; Franco, D. W.; J. Braz. Chem. Soc. 2012, 23, 1506; Serafim, F. A. T.; Da Silva, A. A.; Galinaro, C. A.; Nascimento, E. S. P.; Franco, D. W.; Quim. Nova. 2012, 35, 1412; Odello, L.; Braceschi, G. P.; Seixas, F. R. F.; Da Silva, A. A.; Galinaro, C. A.; Franco, D. W.; Quim. Nova. 2009, 32,1839 .

35. http://www.ibrac.net, acessada em agosto de 2017.

36. Toledo, C. E. M.; Britta, E. A.; Ceole, L. F.; Silva, E. R.; Mello, J. C. P.; Dias Filho, B. P.; Nakamura, C. V.; Ueda-Nakamura, T.; J. Ethnopharmacol. 2011, 133, 420.

37. Souza, P. T.; Rossi, A. V.; Quim. Nova 2014, 37, 631.

38. Braibante, H. T. S.; Química Orgânica: um Curso Experimental, Editora Átomo: Campinas, 2015; Fieser, L. F.; Experiments in Organic Chemistry, $3^{\text {rd }}$ ed., D. C. Heath and Company: Boston, 1955; Mano, E. B.; Seabra, A. O.; Práticas de Química Orgânica, $3^{\mathrm{a}}$ ed., Editora Edgard Blucher LTDA: São Paulo, 1987; Soares, B. G.; Souza, N. A.; Pires, D. X.; Química Orgânica: Teoria e Técnicas de Preparação, Purificação e Identificação de Compostos Orgânicos, Ed. Guanabara S.A.: Rio de Janeiro, 1988; Furniss, B. S.; Hannaford, A. J.; Smith, P. W. G.; Tactchell, A. R.; Vogel's Textbook of Practical Organic Chemistry, $5^{\text {th }}$ ed., Longman Scientific \& Technical: Singapore, 1989; Harwood, L. M.; Moody, C. J.; Experimental Organic Chemistry: Principles and Practice, Blackwell Science: Great Britain, 1989; Roberts, M. R.; Gilbert, J. C.; Martin, S. F.; Experimental Organic Chemistry: a Miniscale Approach, Saunders College Publishing: Phyladelphia, 1994; Dias, A. G.; da Costa, M. A.; Guimarães, P. I. C.; Guia Prático de Química Orgânica, Vol 2, Síntese Orgânica: Executando Experimentos, Editora Interciência: Rio de Janeiro, 2008; Marques, J. A.; Borges, C. P. F.; Práticas de Química Orgânica, $2^{\mathrm{a}}$ Edição, Editora Átomo: Campinas, 2012; Engel, R. G.; Kriz, G. S.; Lampman, G. M.; Pavia, D. L.; Química Orgânica Experimental. Técnicas de Escala Pequena, $3^{\mathrm{a}}$ ed., Cengage Learning: São Paulo, 2012.

39. Leal, C. M.; de Araújo, D. A.; Pinheiro, P. C.; Quim. Nova Esc. 2012, 34, 58; Pinheiro, P. C.; Leal, C. M.; de Araújo, D. A.; Quim. Nova Esc. 2003, 18, 3.

40. Claisen, L., Claparède, A.; Ber. Dtsch. Chem. Ges. 1881, 14, 349; Claisen, L., Claparède, A.; Ber. Dtsch. Chem. Ges. 1881, 14, 2460.

41. Schmidt, J. G.; Ber. Dtsch. Chem. Ges. 1881, 14, 1459.

42. Hawbecker, B. L.; Kurtz, D. W.; Putnam, T. D.; Ahlers, P. A.; Gerber, G. D. J. Chem. Educ. 1978, 55, 540; Hathaway, B. A.; J. Chem. Educ. 1987, 64, 367; Hull, L. A.; J. Chem. Educ. 2001, 78, 226; Vyvyan, J. R.; Pavia, D. L.; Lampman, G. M.; Kriz G. S.; J. Chem. Educ. 2002, 79, 1119; Palleros, D. R. ; J. Chem. Educ. 2004, 81, 1345; Angelo, N. G.; Henchey, L. K.; Waxman, A. J.; Canary, J. W.; Arora, P. S.; Wink. D.; J. Chem. Educ. 2007, 84, 1816; Mohrig, J. R.; Hammond, C. N. ; Schatz P. F.; Davidson, T. A.; J. Chem. Educ. 2009, 86, 234; Balija, A. M.; Reynolds, A. M.; J. Chem. Educ. 2013, 90, 1100.

43. Informações obtidas em: http://www.ciamuller.com.br, acessada em agosto de 2017.

44. Pinto, A. C.; Quim. Nova Esc. 2001, 13, 49; Pinto, A. C.; Quim. Nova 1995, 18, 608; Almeida, M. R.; Martinez, S. T.; Pinto, A. C.; Rev. Virtual Quim. 2017, 9, 1117.

45. da Costa, C. L. S.; Chaves, M. H.; Quim. Nova 2005, 28, 149.

46. Alves, M. de C.; Cienc. Cult. 2014, 66, 60. 